\title{
Peridynamic Modeling of Fuel Pellet Cracking
}

\author{
Selda Oterkus \\ Department of Naval Architecture, Ocean and Marine Engineering \\ University of Strathclyde \\ Glasgow, United Kingdom \\ Erdogan Madenci \\ Department of Aerospace and Mechanical Engineering \\ University of Arizona \\ Tucson, AZ 85721
}

\begin{abstract}
This study presents the peridynamic simulation of thermal cracking behaviour in uranium dioxide, $\mathrm{UO}_{2}$ fuel pellets that are used in light water reactors (LWR). The performance of the reactor is influenced by the thermo-mechanical behaviour of the pellets. During the fission process, the pellets are subjected to high temperature gradients, and the oxygen diffusion significantly affects the temperature distribution. Therefore, a coupled analysis of temperature and oxygen diffusions and deformation is unavoidable in order to predict accurate cracking behavior in a fuel pellet. The accuracy of the predictions is verified qualitatively by comparing with the previous studies.
\end{abstract}

Keywords: peridynamics, fuel pellet, uranium dioxide, failure

\section{Introduction}

Nuclear fuel pellets are used to generate heat for power generation as a result of fission process. Therefore, it is essential to understand its thermal transport for enhancing power output and preventing potential accidents. Uranium dioxide $\left(\mathrm{UO}_{2}\right)$ is the main component of the fuel pellet. Its composition can have both an excess and deficiency of oxygen relative to stoichiometric $\mathrm{UO}_{2}$ (Kurepin, 2002). Studies by show that in hyper-stoichiometric Urania $\left(\mathrm{UO}_{2}+\mathrm{x}\right)$, the oxygen ions tend to accumulate in the regions of high temperature gradient or the Soret effect (the transport of oxygen atoms due to a temperature gradient) (Aitken, 1969 and Ramirez, 2006). It is experimentally found that the thermal conductivity of $\mathrm{UO}_{2}$ decreases with temperature (Lucuta et al., 1996) and with increasing non-stoichiometry (Amaya et al, 1996). The fuel pellets are placed in a cladding and there exists a gap between fuel pellet and the cladding. The cooling water passing through the fuel elements extracts heat from the nuclear fuels (Chernatynskiy et al, 2015). However, significant microstructural changes and deterioration of the fuel pellet occur due to the fission process. As a result, the degraded physical state of the fuel becomes the limiting factor for long term and transient reactor performance (Brutzel et al. 2015). 
As the fuel temperature increases, radial cracks occur and propagate towards the center of fuel pellet. Also, circumferential crack patterns develop during a steady-state operation. Cracking patterns significantly affect the fuel thermal conductivity and neutron diffusion coefficient. Therefore, it influences the overall pellet thermal expansion; thus, the gap closure occurs between the pellet and clad. Moreover, the oxygen diffusion affects the thermal conductivity which leads to an increase in temperature. Hence, the analysis of fuel pellet behavior requires a fully coupled consideration of thermal diffusion, oxygen diffusion, deformation and cracking process.

The Finite Element Method (FEM) has been extensively used by Ito et al. (1983), Lassmann (1992), Berna et al. (1997) and Gates et al. (1998) while disregarding the coupling of multiphysics modeling and crack propagation in fuel pellets. Also, they simulated the fuel rod behavior in the radial direction under axisymmetric assumptions. Furthermore, Ramirez et al. (2006) performed finite element simulations to couple heat and oxygen diffusion for $\mathrm{UO}_{2}$ fuel rods in one-dimensional (radial) configurations by using COMSOL Multiphysics, a commercially available software. Their study revealed the influence of oxygen on thermal conductivity which significantly increases the maximum temperature in a fuel rod. Newman et al. (2009) coupled thermomechanics with heat and oxygen diffusion in $\mathrm{UO}_{2}$ fuel rods. They coupled the governing equations through the material properties that are functions of density, temperature and oxygen concentration, and investigated the opening of a pre-determined crack in a fuel rod due to thermal expansion. Mihaila et al. (2009) studied the coupling of thermomechanics with heat and oxygen diffusion in $\mathrm{UO}_{2}$ fuel elements by using COMSOL Multiphysics. In their study, they presented one-dimensional simulations; thus, it did not include crack propagation in fuel pellets.

Williamson and Knoll (2009) simulated the discrete dynamic fracturing of nuclear fuel by using cohesive zone elements under thermomechanical loads. The cohesive surfaces are placed along the potential crack paths, and the cohesive crack initiation is triggered at locations where the maximum principal stress reaches the fracture strength. Williamson (2011) also tested smeared cracking approximation of pellets and compared with discrete fuel pellet analysis. This study revealed that smeared pellet simulation predicts slightly higher temperatures and delay in gap closure.

Rashid et al. (2011) performed a two-dimensional finite element analysis to predict thermal, mechanical and chemical behavior of a fuel rod during irradiation by assuming a predetermined crack location. Williamson et al. (2012) performed a multi-dimensional multi-physics finite element analysis of nuclear fuel pellets by including fracture via relocation and smeared crack models. Recently, Sercombe et al. (2016) used FEM to simulate hydride blister cracking in fuel pellets. When a pre-determined hoop stress is exceeded at the clad outer surface, a radial cracking of the blister is introduced in the simulation by modifying the boundary conditions.

Majority of the aforementioned FE models introduced cracks at a priori known crack paths. However, such paths are not available prior to the analysis. The presence of stress singularity at the crack tips and material heterogeneity introduce additional challenges in predicting crack initiation sites. By using Discrete Element Method (DEM), Huang et al. (2014) removed these 
challenges, and simulated thermally driven randomly initiated cracks in fuel pellets. They were able to predict radial and circumferential cracks in a fuel pellet.

Alternative to DEM is the peridynamic theory which is based on the integral-differential equations and free of spatial derivatives (Silling, 2000). Although its governing equations are solved numerically through discretization, it is based on the assumptions of nonlocal continuum mechanics. Also, it enables crack nucleation and propagation without an external failure criteria. Mella and Wenman (2015) predicted the fracture behavior of a pellet for specified (precomputed) temperature profiles by using peridynamics. The present study also employs peridynamics to predict cracking in a fuel pellet while considering the fully coupled field equations of heat and oxygen diffusion and mechanical deformations. The material properties are dependent on temperature and oxygen concentration. The accuracy of the predictions is verified both quantitatively and qualitatively by comparing with the previous studies and finite element analysis prediction.

\section{Pellet thermomechanical model}

The peridynamic equation of motion was introduced by Silling (2000) as

$$
\rho(C, \Theta) \ddot{\mathbf{u}}(\mathbf{x}, t)=\int_{H} \mathbf{f}\left(\mathbf{x}^{\prime}-\mathbf{x}, \mathbf{u}^{\prime}-\mathbf{u}\right) d V^{\prime}+\mathbf{b}(\mathbf{x}, t)
$$

where $\mathbf{u}(\mathbf{x}, t)$ and $\mathbf{b}(\mathbf{x}, t)$ represent the displacement and body force density vectors at material point, $\mathbf{x}$. The force density vector including the thermal effects is suggested by Kilic and Madenci (2010a) as

$$
\mathbf{f}=c(C, \Theta)\left[s-\alpha(\Theta) T_{a v g}(\Theta)\right] \frac{\left(\mathbf{x}^{\prime}+\mathbf{u}^{\prime}\right)-(\mathbf{x}+\mathbf{u})}{\left|\left(\mathbf{x}^{\prime}+\mathbf{u}^{\prime}\right)-(\mathbf{x}+\mathbf{u})\right|}
$$

where $\Theta$ and $C$ represent temperature and oxygen concentration, respectively. The stretch between two material points $\mathbf{x}$ and $\mathbf{x}^{\prime}$ is defined as

$$
s=\frac{\left|\left(\mathbf{x}^{\prime}+\mathbf{u}^{\prime}\right)-(\mathbf{x}+\mathbf{u})\right|-\left|\mathbf{x}^{\prime}-\mathbf{x}\right|}{\left|\mathbf{x}^{\prime}-\mathbf{x}\right|}
$$

The material parameter $c$ is derived by Gerstle et al. (2005) as a function of elastic modulus, $E$, thickness, $h$ and horizon size, $\delta$ as $c=\frac{9 E}{\pi h \delta^{3}}$ for $2 \mathrm{D}$ and $c=\frac{12 E}{\pi \delta^{4}}$ for $3 \mathrm{D}$, and $\alpha$ is the coefficient of thermal expansion. The mean value of the change in temperatures, $T_{a v g}$ at material points $\mathbf{x}$ and $\mathbf{x}^{\prime}$, is defined as

$$
T_{a v g}=\frac{\left(\Theta-\Theta_{0}\right)+\left(\Theta^{\prime}-\Theta_{0}\right)}{2}
$$


in which $\Theta$ and $\Theta^{\prime}$ represent the temperature at material points $\mathbf{x}$ and $\mathbf{x}^{\prime}, \Theta_{0}$ represents the reference temperature.

Failure process begins when the stretch between the two material points, $\mathbf{x}$ and $\mathbf{x}^{\prime}$ exceeds a critical stretch value, $s_{c r}$. The critical stretch value can be obtained from the critical energy release rate of the material, $G_{c}$ as (Silling and Askari, 2005)

$$
s_{c r}=\sqrt{\frac{\pi G_{c}}{3 \kappa \delta}} \text { for 2D and } s_{c r}=\sqrt{\frac{5 G_{c}}{9 \kappa \delta}} \text { for 3D }
$$

Damage initiation is included in the PD equation of motion, Eq. (1a) by introducing a historydependent status parameter $\mu$ (Silling and Askari, 2005) as

$$
\rho(\mathbf{x}) \ddot{\mathbf{u}}(\mathbf{x}, t)=\int_{H} \mu \mathbf{f}\left(\mathbf{x}^{\prime}-\mathbf{x}, \mathbf{u}^{\prime}-\mathbf{u}\right) d V^{\prime}+\mathbf{b}(\mathbf{x}, t)
$$

where

$$
\mu\left(\mathbf{x}^{\prime}-\mathbf{x}, t\right)=\left\{\begin{array}{lll}
1 & \text { if } & s<s_{c r} \\
0 & \text { if } & s>s_{c r}
\end{array}\right.
$$

Local damage at material points, $\mathbf{x}$ is defined as the ratio of removed interactions to total number of its interactions within its horizon (Silling and Askari, 2005). It is expressed as

$$
\varphi\left(\mathbf{x}^{\prime}-\mathbf{x}, t\right)=1-\frac{\int_{H} \mu\left(\mathbf{x}^{\prime}-\mathbf{x}, t\right) d V^{\prime}}{\int_{H} d V^{\prime}}
$$

It has a value between 0 and 1 . There is no damage for $\varphi=0$ while $\varphi=1$ denotes that all the interactions are removed.

\section{Pellet heat conduction model}

Inside the pellet, it is assumed that fission reaction creates uniformly distributed heat generation (Ramirez et al., 2006; Newman et al., 2009; Huang et al., 2014). The heat equation inside the pellet can be expressed as

$$
\rho(\Theta) c_{p}(\Theta) \frac{\partial \Theta}{\partial t}=k(\Theta, C) \nabla^{2} \Theta+Q
$$

where $\Theta$ is the temperature, $\rho(\Theta)$ is the density, $k(\Theta, C)$ is the thermal conductivity, $c_{p}(\Theta)$ is the specific heat and $Q$ is the volumetric heat source of the pellet. 
The parameter, $C$ denotes the oxygen concentration. As shown by Oterkus et al. (2014), the PD form of heat conduction model can be derived as

$$
\rho(\Theta) c_{p}(\Theta) \frac{\partial \Theta}{\partial t}=\int_{H} f_{T}\left(\Theta^{\prime}, \Theta, \mathbf{x}^{\prime}, \mathbf{x}, t\right) d V_{\mathbf{x}^{\prime}}+Q(\mathbf{x}, t)
$$

where $f_{T}$ is the thermal response function that governs the interaction between material points $\mathbf{x}$ and $\mathbf{x}^{\prime}$. It is derived as

$$
f_{T}\left(\Theta^{\prime}, \Theta, \mathbf{x}^{\prime}, \mathbf{x}, t\right)=\kappa_{T}(\Theta, C) \frac{\Theta^{\prime}\left(\mathbf{x}^{\prime}, t\right)-\Theta(\mathbf{x}, t)}{\left|\mathbf{x}^{\prime}-\mathbf{x}\right|}
$$

in which $\kappa_{T}$ is a PD material parameter, and referred to as the micro-conductivity. Depending on the analysis dimension, it can be expressed in terms of thermal conductivity $k$, thickness, $h$ and horizon size $\delta$ as $\kappa_{T}=\frac{6 k}{\pi h \delta^{3}}$ for $2 \mathrm{D}$ and $\kappa_{T}=\frac{6 k}{\pi \delta^{4}}$ for $3 \mathrm{D}$.

\section{Pellet oxygen diffusion model}

The oxygen diffusion in fuel pellets is governed by (Newman et al., 2009)

$$
\frac{\partial C}{\partial t}+\nabla \cdot \mathbf{J}=0
$$

where $C$ is the oxygen concentration and $\mathbf{J}$ is the oxygen flux. The oxygen diffusion flux is defined as

$$
\mathbf{J}=\mathbf{J}_{C}+\mathbf{J}_{T}
$$

in which

$$
\mathbf{J}_{C}=-D(\Theta) \nabla C
$$

and

$$
\mathbf{J}_{T}=-\frac{D(\Theta) Q^{*}(C)}{F(C)} \frac{C}{R \Theta^{2}} \nabla \Theta
$$

In these equations, $D(\Theta)$ is the diffusivity of $\mathrm{UO}_{2}, Q^{*}(C)$ is the heat of transport of oxygen $(\mathrm{J} / \mathrm{mol}), F(C)$ is the nondimensional thermodynamic factor of oxygen and $R$ is the universal gas constant. In Eq. 13b $\mathbf{J}_{T}$ is the Soret flux representing the flux of oxygen due to temperature 
gradient, and $\mathbf{J}_{C}$ is the Fickian flux representing the flux of oxygen due to concentration gradient. These fluxes are responsible for the variation of oxygen concentration in the fuel pellet. The heat of transport of oxygen, $Q^{*}(C)$ determines the direction and the degree of the segregation. It is negative and the ions tend to accumulate in the regions of high temperature gradient (Janek and Timm, 1998, Ramirez et al., 2006). The factor $F(C)$ relates the change in composition with a change in the oxygen activity (Janek and Timm, 1998).

The corresponding PD form of the diffusion flux can be written as (Madenci and Oterkus, 2016)

$$
\mathbf{J}_{C}=-\frac{1}{2} \int_{H} f_{D C}\left(C^{\prime}, C, \mathbf{x}^{\prime}, \mathbf{x}, t\right)\left(\mathbf{x}^{\prime}-\mathbf{x}\right) d V_{\mathbf{x}^{\prime}}
$$

and

$$
\mathbf{J}_{T}=-\frac{1}{2} \int_{H} \frac{C_{a v e} Q^{*}(C)}{F(C) R \Theta_{\text {ave }}^{2}} f_{D T}\left(\Theta^{\prime}, \Theta, \mathbf{x}^{\prime}, \mathbf{x}, t\right)\left(\mathbf{x}^{\prime}-\mathbf{x}\right) d V_{\mathbf{x}^{\prime}}
$$

where $f_{D C}$ and $f_{D T}$ are the response functions that govern the oxygen diffusion transfer due to concentration gradient and temperature gradient, respectively, as

$$
f_{D C}\left(\Theta^{\prime}, \Theta, \mathbf{x}^{\prime}, \mathbf{x}, t\right)=\kappa_{D C} \frac{C^{\prime}\left(\mathbf{x}^{\prime}, t\right)-C(\mathbf{x}, t)}{\left|\mathbf{x}^{\prime}-\mathbf{x}\right|}
$$

and

$$
f_{D T}\left(\Theta^{\prime}, \Theta, \mathbf{x}^{\prime}, \mathbf{x}, t\right)=\kappa_{D T} \frac{\Theta^{\prime}\left(\mathbf{x}^{\prime}, t\right)-\Theta(\mathbf{x}, t)}{\left|\mathbf{x}^{\prime}-\mathbf{x}\right|}
$$

where $f_{D C}$ and $f_{D T}$ are the response functions that govern the oxygen diffusion transfer due to concentration gradient and temperature gradient, respectively.

In Eq. (14b), the parameters $C_{a v e}$ and $\Theta_{\text {ave }}$ are defined as

$$
C_{a v e}=\frac{C+C^{\prime}}{2}
$$

and

$$
\Theta_{\text {ave }}=\frac{\Theta+\Theta^{\prime}}{2}
$$

As derived in the appendix, the PD form of the oxygen diffusion in fuel pellets can be expressed as 


$$
\frac{\partial C}{\partial t}=\frac{-\kappa_{J}}{2} \int_{H}\left(\left(J_{x}^{\prime}\left(\mathbf{x}^{\prime}, t\right)-J_{x}(\mathbf{x}, t)\right) \frac{x^{\prime}-x}{\left|\mathbf{x}^{\prime}-\mathbf{x}\right|}+\left(J_{y}^{\prime}\left(\mathbf{x}^{\prime}, t\right)-J_{y}(\mathbf{x}, t)\right) \frac{y^{\prime}-y}{\left|\mathbf{x}^{\prime}-\mathbf{x}\right|}\right) d V_{\mathbf{x}^{\prime}}
$$

with the parameter $\kappa_{J}$ which can be expressed as a function of thickness, $h$ and horizon size $\delta$ such as $\kappa_{J}=\frac{6}{\pi h \delta^{3}}$ for $2 \mathrm{D}$ and $\kappa_{J}=\frac{6}{\pi \delta^{4}}$ for $3 \mathrm{D}$.

\section{Numerical results}

Numerical results demonstrate the capability of peridynamics for crack nucleation at multiple sites and their simultaneous complex growth patterns. Prior to the prediction of cracking, the accuracy of this approach is established by comparison with finite element analysis predictions in the absence of cracking. As part of verification, the fuel pellet is subjected to: a constant heat source in the absence of oxygen diffusion, a constant heat source in the presence of oxygen diffusion, and a constant heat source in the absence of oxygen diffusion while allowing for mechanical deformation. As part of demonstration, the crack nucleation and its propagation is allowed in the fuel pellet due to: a constant heat source in the absence of oxygen diffusion, a varying heat source in the absence of oxygen diffusion, and a varying heat source in the presence of oxygen diffusion.

The nuclear fuels are operated on the order of days and months. However, the predictions are based on very short computational time to demonstrate the capability. The realistic time consideration will certainly change the temperature variation in time. The mechanical deformations and cracking are predicted through a one-way coupling due to the temperature field at a specific time (Ramirez et al. 2006). Although, the peridynamic form of the thermomechanical equation includes the inertial term, the quasi-static solution is obtained by using Adaptive Dynamic Relaxation (ADR) method (Kilic and Madenci, 2010b). Time integration is achieved by using explicit time integration for the solution of heat and oxygen concentration.

The PD model for the fuel pellet is shown in Fig. 1. The radius of the pellet is specified as $r_{p}=4.3 \times 10^{-3} \mathrm{~m}$. The model domain is discretized with 52213 material points. In the case of a constant heat source and oxygen concentration, they are specified as $C_{o}=0.01$ and $Q=2 \times 10^{8} \mathrm{~W} / \mathrm{m}^{3}$ to represent the fusion reaction (Ramirez et al, 2006). The reference temperature and the outer surface temperature of the pellet are assumed as $\Theta_{0}=273{ }^{\circ} \mathrm{K}$ and $\Theta^{*}\left(r_{p}, t\right)=810{ }^{\circ} \mathrm{K}$, respectively. It is initially at $\Theta(r, t=0)=810{ }^{\circ} \mathrm{K}$, and the outer boundary is stress free.

In the case of varying heat source, the heat source distribution is specified as 


$$
Q=\left\{\begin{array}{clr}
2 \times 10^{8} & \left(\mathrm{~W} / \mathrm{m}^{3}\right), & t<4.5 s \\
2 \times 10^{8}\left(1-\frac{t-4.5}{4.5}\right) & \left(\mathrm{W} / \mathrm{m}^{3}\right), 9 s>t>4.5 s
\end{array}\right.
$$

In the case of oxygen diffusion, its initial value is $C(r, t=0)=C_{o}=0.01$ with a specified value on the pellet boundary as $C\left(r_{p}, t\right)=C^{*}=0.02$.

The heterogeneity of the material properties are represented by using Gaussian distribution. As shown in Fig. 2, the randomized factors for elastic modulus are generated from a Gaussian distribution with a mean value of $\mu=1$ and a standard deviation of $\sigma=0.1$. These randomized values represent the inhomogeneity in the real material. The critical stretch, $s_{c r}$ is also randomized by using the Gaussian distribution with a mean value of $\mu=0.001$ and standard deviation of $\sigma=0.1$. When the interaction between the two material points is removed, it is assumed that no heat transfer occurs between them.

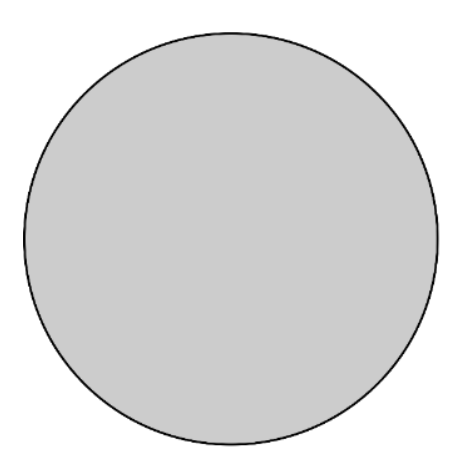

(a)

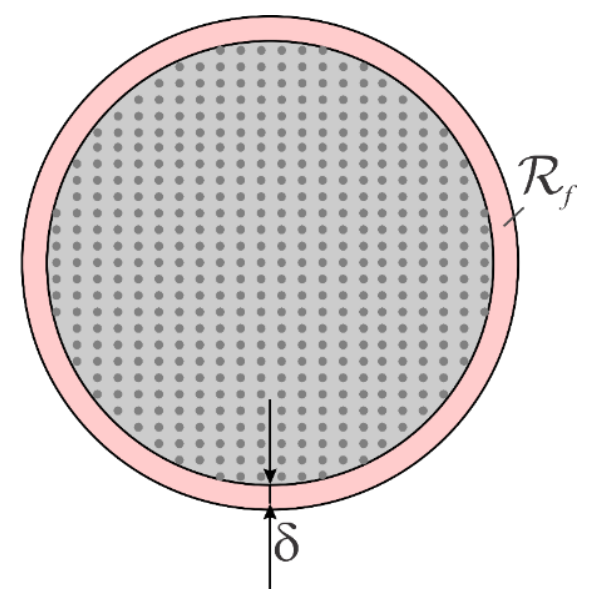

(b)

Fig. 1. Fuel Pellet (a) Geometry (b) PD model

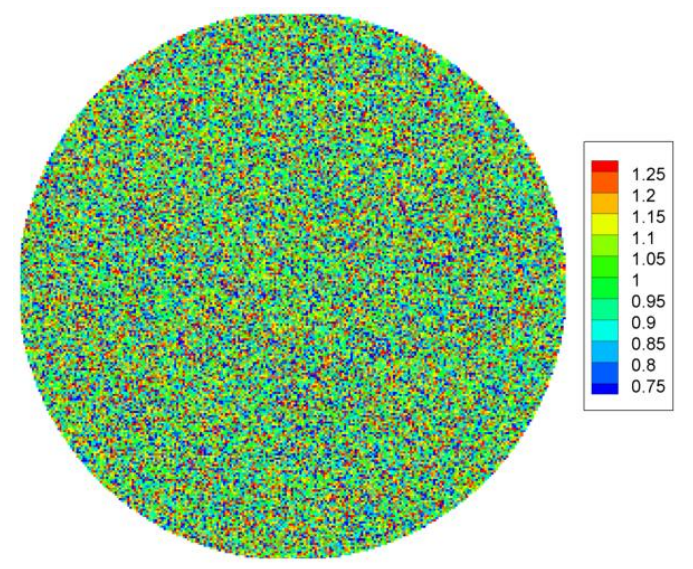

Fig. 2. Randomized factors for elastic modulus and critical stretch. 
The material and physical properties of the $\mathrm{UO}_{2}$ fuel pellet are specified according to Newman et al. (2009). The elastic modulus, $E(C, \Theta)$ and thermal expansion coefficient, $\alpha(\Theta)$ are specified as

$$
E(C, \Theta)=2.0128416 \times 10^{11}\left(1-1.0915 \times 10^{-4} \Theta\right) \exp (-1.75 C)(\mathrm{Pa})
$$

and

$$
\alpha(\Theta)=\left(a+b \Theta+c \Theta^{2}+d \Theta^{3}\right)\left(\frac{1}{{ }^{\circ} \mathrm{K}}\right)
$$

where

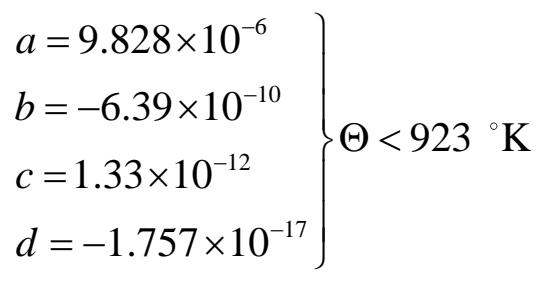

and

$$
\begin{aligned}
& a=1.1833 \times 10^{-5} \\
& b=-5.013 \times 10^{-9} \\
& \left.\begin{array}{l}
c=3.756 \times 10^{-12} \\
d=-6.125 \times 10^{-17}
\end{array}\right\} \Theta>923{ }^{\circ} \mathrm{K}
\end{aligned}
$$

The specific heat, $c_{p}(\Theta)$, density $\rho(\Theta)$ and thermal conductivity $k(C, \Theta)$ are specified as

$$
\begin{aligned}
& c_{p}(\Theta)=264.256+0.047 \Theta\left(\frac{\mathrm{J}}{\mathrm{kg}^{\circ} \mathrm{K}}\right) \\
& \rho(\Theta)=10960\left(a+b \Theta+c \Theta^{2}+d \Theta^{3}\right)^{-3}\left(\frac{\mathrm{kg}}{\mathrm{m}^{3}}\right)
\end{aligned}
$$

where

$$
\left.\begin{array}{l}
\begin{array}{l}
a \\
=0.997 \\
b
\end{array}=9.802 \times 10^{-6} \\
c=-2.705 \times 10^{-10} \\
d=4.391 \times 10^{-13}
\end{array}\right\} \Theta<923{ }^{\circ} \mathrm{K}
$$


and

$$
\begin{aligned}
& \left.\begin{array}{l}
a=0.997 \\
b=1.179 \times 10^{-5} \\
c=-2.429 \times 10^{-9} \\
d=1.219 \times 10^{-12}
\end{array}\right\} \Theta>923{ }^{\circ} \mathrm{K} \\
& k(\Theta, C)=\lambda_{o}(\Theta) \frac{\arctan (\theta(\Theta, C))}{\theta(\Theta, C)}+5.95 \times 10^{-11} \Theta^{3}\left(\frac{\mathrm{W}}{\mathrm{m}^{\circ} \mathrm{K}}\right) .
\end{aligned}
$$

where

$$
\theta(\Theta, C)=3.67 \exp \left(-4.73 \times 10^{-4} \Theta\right) \sqrt{2 C \lambda_{o}(\Theta)}
$$

and

$$
\lambda_{o}(\Theta)=\left(3.24 \times 10^{-2}+2.51 \times 10^{-4} \Theta\right)^{-1}
$$

The diffusivity, $D(\Theta)$, heat of transport of oxygen, $Q^{*}(C)$ and the thermodynamic factor of oxygen, $F(C)$ are specified as

$$
\begin{aligned}
& D(\Theta)=2.5 \exp \left(-\frac{16400}{\Theta}\right)\left(\frac{\mathrm{cm}^{2}}{\mathrm{~s}}\right) \\
& Q^{*}(C)=-1380.8-134435.5 \exp \left(-\frac{C}{0.02261}\right)\left(\frac{\mathrm{J}}{\mathrm{mol}}\right) \\
& F(C)=\left(\frac{2+C}{2(1-3 C)(1-2 C)}\right)
\end{aligned}
$$

The prescribed boundary values of temperature and oxygen concentration are imposed through a fictitious region, $\mathcal{R}_{f}$ as (Oterkus and Madenci, 2015)

$$
\begin{aligned}
& \Theta_{f}\left(r_{f}, t+\Delta t\right)=2 \Theta^{*}\left(r^{*}, t+\Delta t\right)-\Theta(\mathrm{r}, t) \\
& C_{f}\left(r_{f}, t+\Delta t\right)=2 C^{*}\left(r^{*}, t+\Delta t\right)-C(\mathrm{r}, t)
\end{aligned}
$$

with 


$$
\left(r^{*}\right) \in \mathcal{S},\left(r_{f}\right) \in \mathcal{R}_{f},(r) \in \mathcal{R}
$$

\subsection{Heat diffusion in a pellet in the absence of oxygen diffusion}

In the absence of cracking, the temperature distribution inside the fuel pellet is investigated due to only a constant heat source of $Q=2 \times 10^{8} \mathrm{~W} / \mathrm{m}^{3}$ to represent the fusion reaction (Ramirez et al, 2006). Fig. 3 shows the steady-state temperature distribution predicted by the peridynamic simulation against the finite element predictions using ANSYS, a commercially available software. The results are in close agreement with each other.

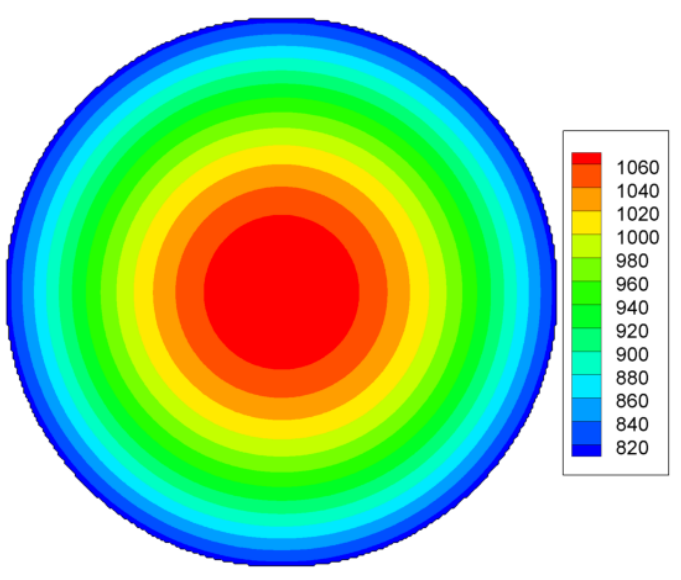

(a)

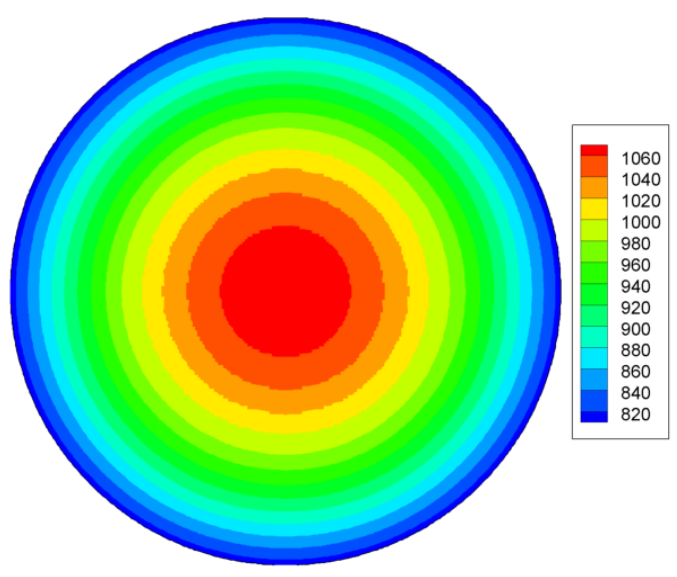

(b)

Fig. 3. Temperature distribution in the fuel pellet $\left({ }^{\circ} \mathrm{K}\right)$ : (a) PD and (b) ANSYS solutions.

\subsection{Heat diffusion in a pellet in the presence of oxygen diffusion}

In the absence of cracking, the effect of oxygen diffusion on temperature distribution is investigated. Fig. 4 shows the temperature distribution for uniform oxygen concentration and with oxygen diffusion. Since the thermal conductivity decreases with increasing oxygen concentration, higher temperature gradients develop due to oxygen diffusion. These results agree well with those reported by (Ramirez et al., 2006). 


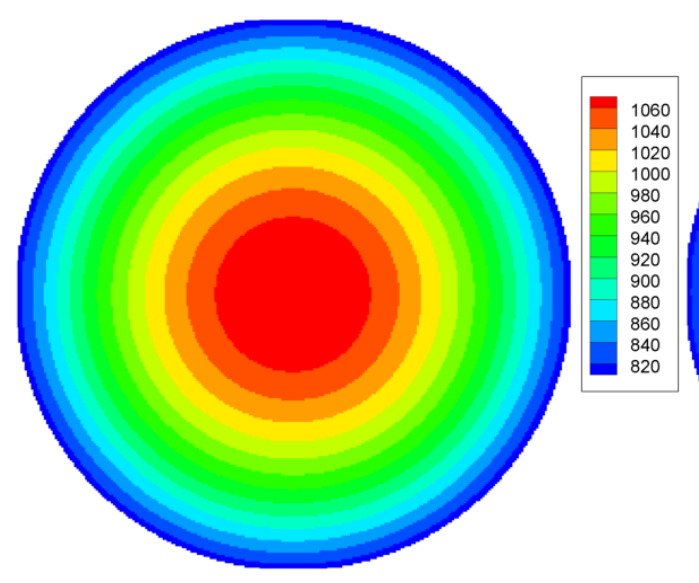

(a)

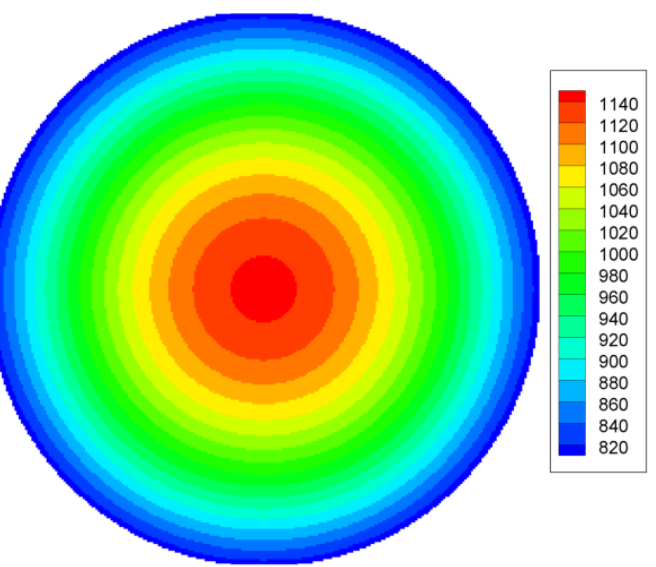

(b)

Fig. 4. Temperature distribution $\left({ }^{\circ} \mathrm{K}\right)$ in the fuel pellet: a) uniform oxygen concentration and b) oxygen diffusion

\subsection{Thermomechanical analysis of fuel pellet}

In the absence of cracking, the effect of temperature distribution on fuel pellet deformation is investigated for a constant heat source and a constant oxygen concentration. The results are compared with the ANSYS predictions. The displacement fields are shown in Figs. 5-6. Due to the thermal loading, the pellet expands in radial direction. The predictions are in close agreement indicating the accuracy of PD thermomechanical model.

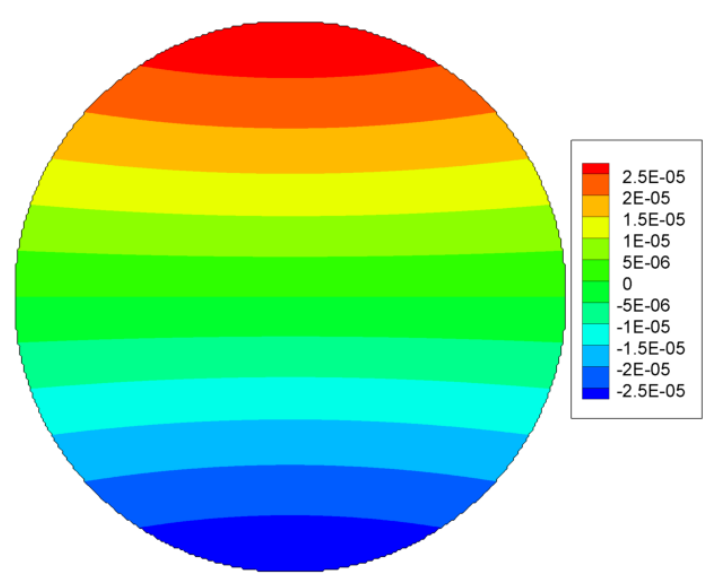

(a)

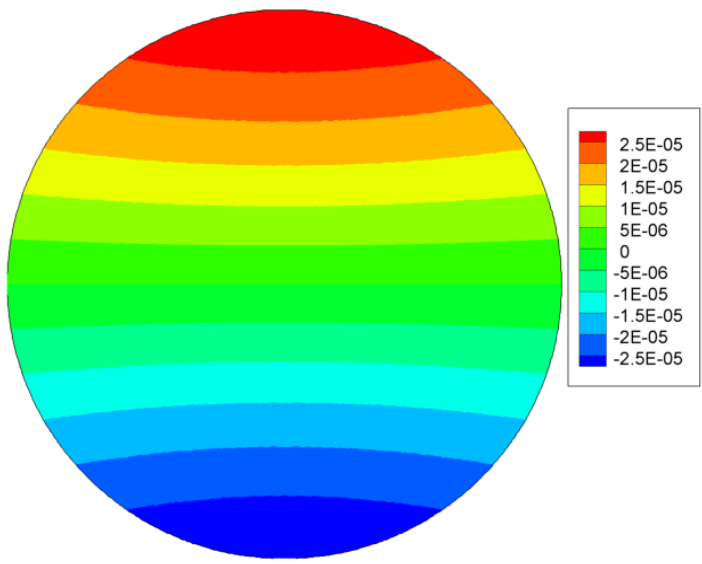

(b)

Fig. 5. Vertical displacement (m): a) PD and b) ANSYS solutions 


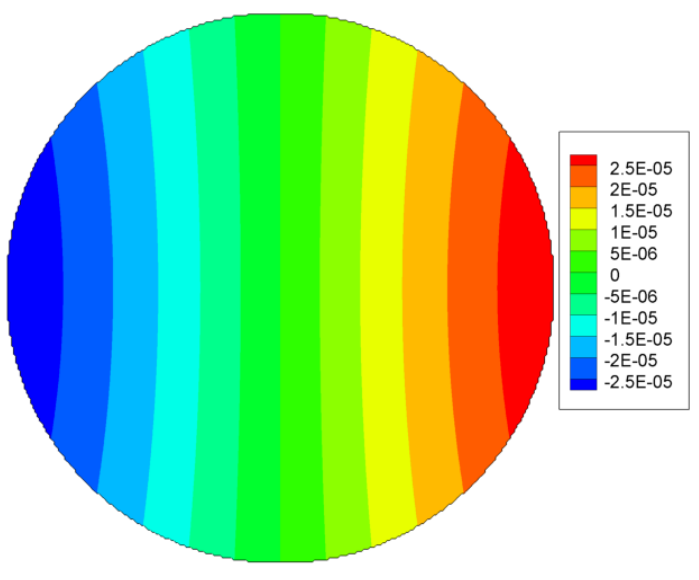

(a)

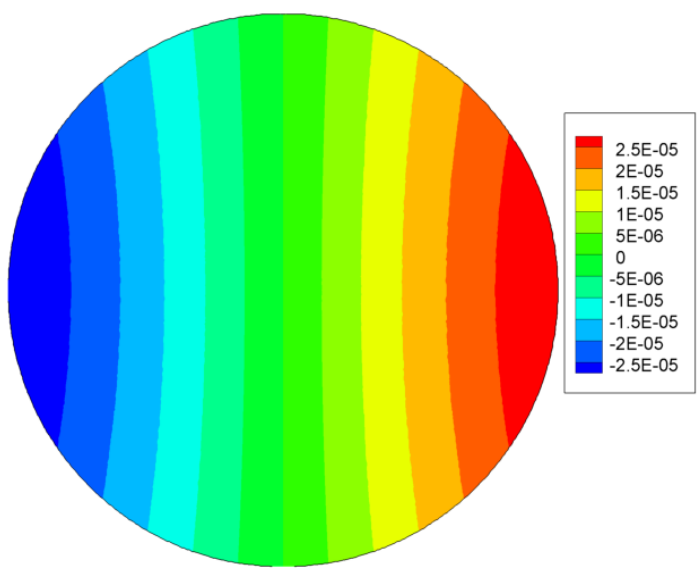

(b)

Fig. 6. Horizontal displacement ( $\mathrm{m})$ : a) PD and b) ANSYS solutions

\subsection{Cracking in a fuel pellet due to constant heat source in the absence of oxygen diffusion}

As the temperature increases, stronger temperature gradients develop in the pellet (Figs. 711). Since higher temperatures develop at the core of the pellet, the center is under compression and the outer region is under tensile stress. Due to this stress distribution, radial cracks emerge at the outer region of the pellet. The damage plots and the corresponding temperature profiles at different times are shown in Figs. 7-11. As the temperature increases, radial cracks start to occur. The cracks grow towards the center as time progresses. As the cracks propagate, discontinues temperature distributions are observed due the presence of cracks. As expected, the crack pattern affects the temperature profile and the temperature profile affects the mechanical deformation. During the simulation four dominant cracks are observed, and they all grow radially. These crack patterns are similar to those obtained by Huang et al. (2014).
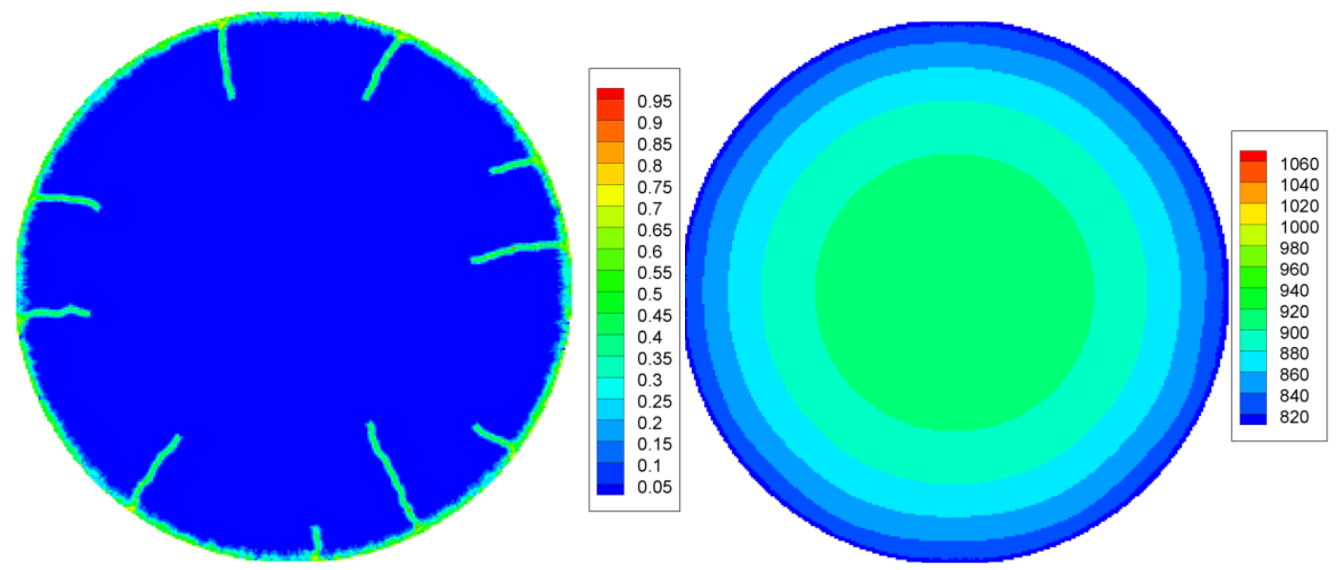

Fig. 7. PD crack initiation and propagation paths, and the corresponding temperature in the fuel pellet at $t=1.8 \mathrm{~s}$ 


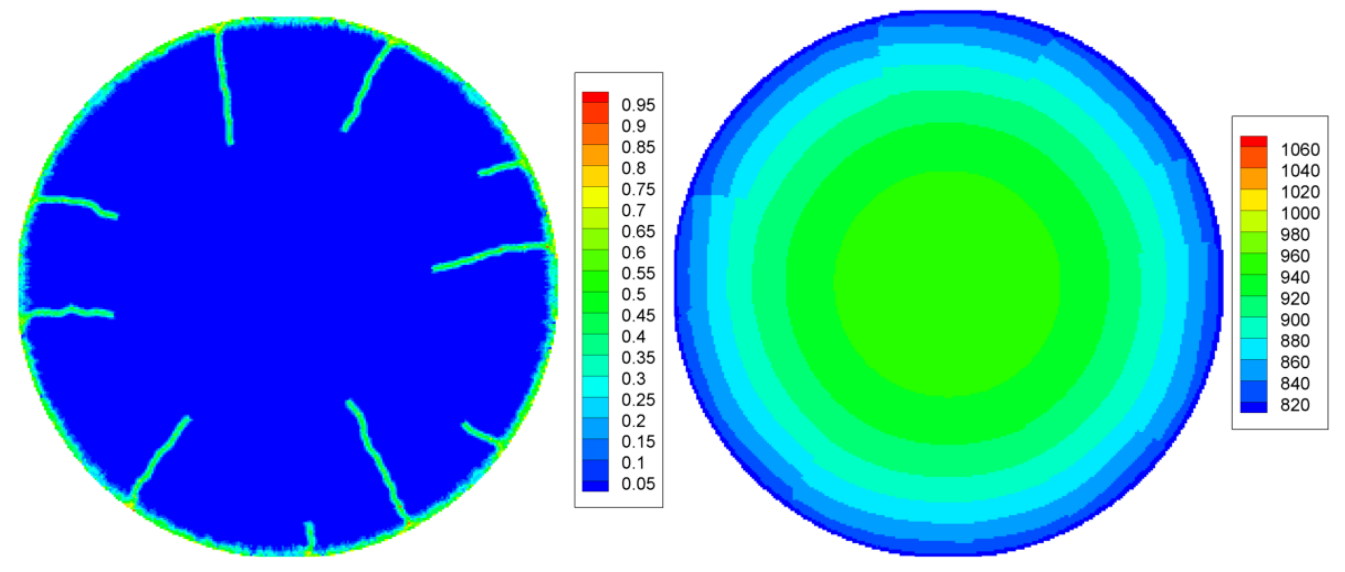

Fig. 8. PD crack initiation and propagation paths, and the corresponding temperature in the fuel pellet at $t=2.7 \mathrm{~s}$
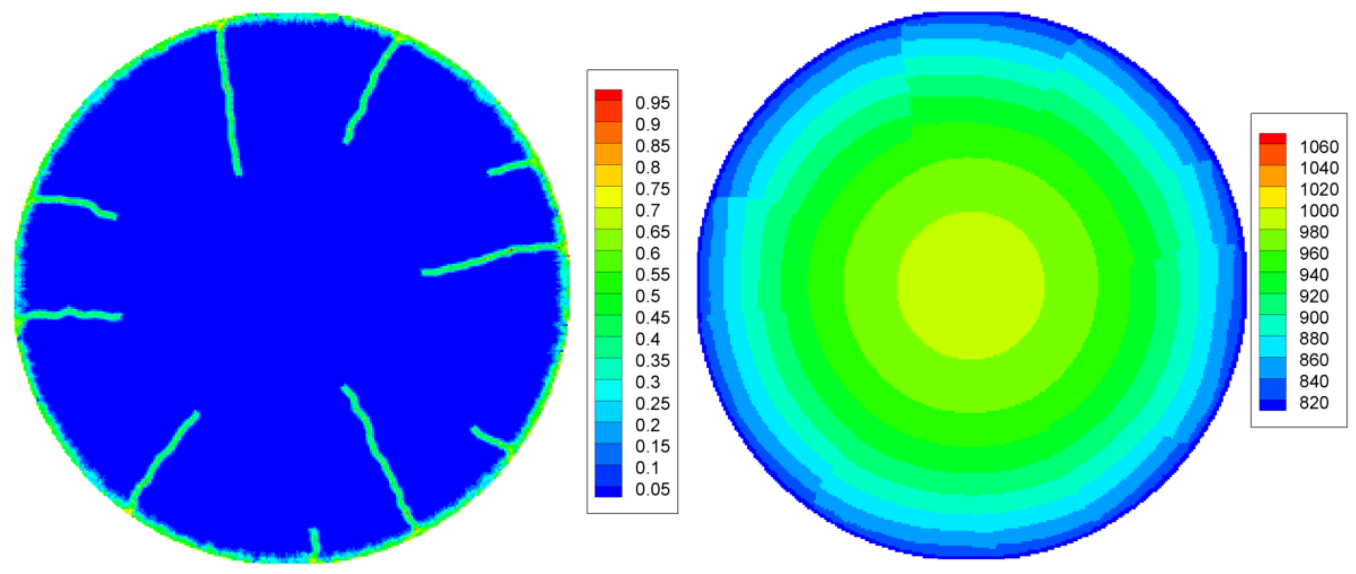

Fig. 9. PD crack initiation and propagation paths, and the corresponding temperature in the fuel pellet at $t=3.6 \mathrm{~s}$ 

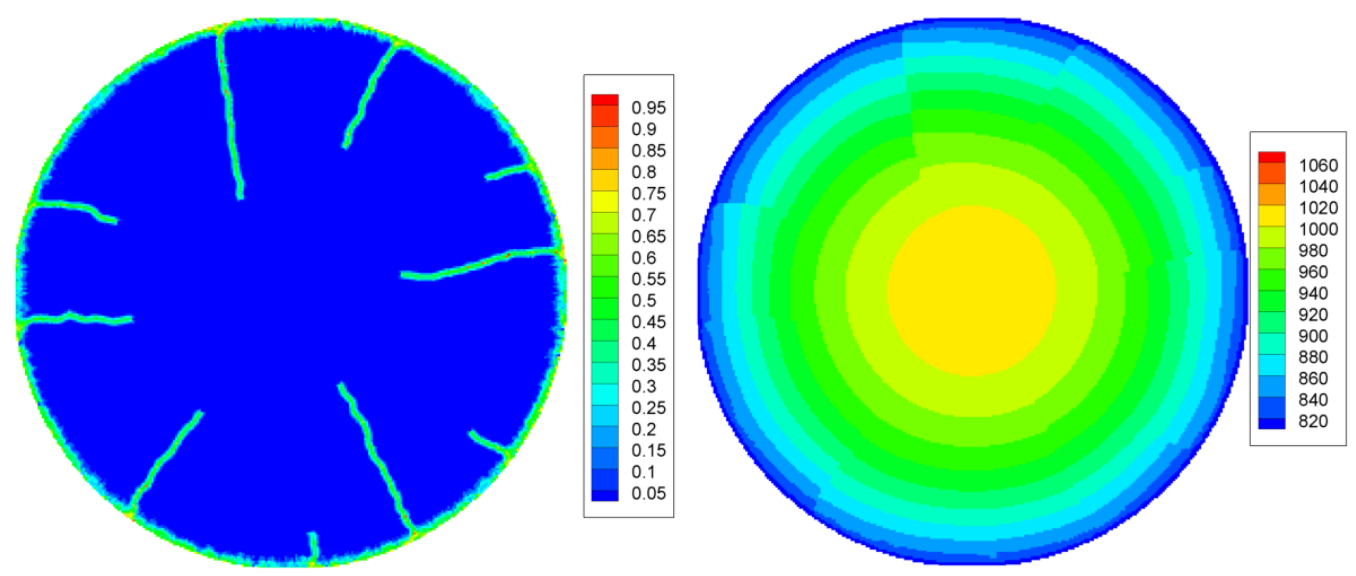

Fig. 10. PD crack initiation and propagation paths, and the corresponding temperature in the fuel pellet at $t=4.5 \mathrm{~s}$
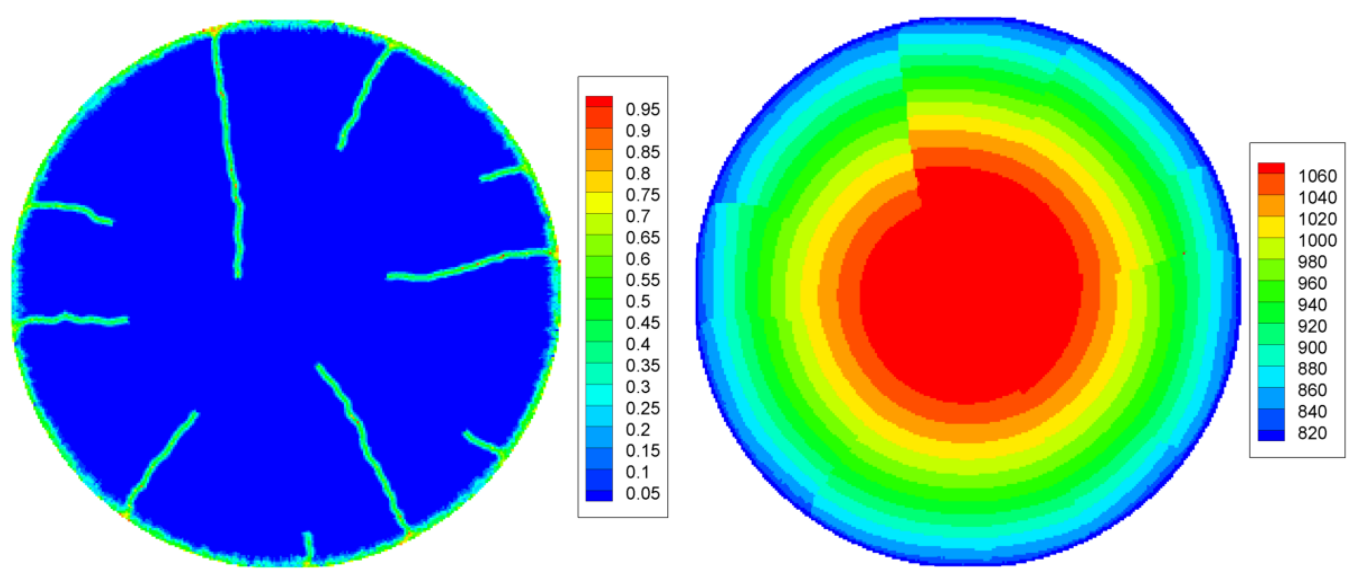

Fig. 11. PD crack initiation and propagation paths, and the corresponding temperature in the fuel pellet at $t=45 \mathrm{~s}$

\subsection{Cracking in a fuel pellet due to varying heat source in the absence of oxygen diffusion}

The varying heat source distribution is specified as given in Eq. (18). It is representative of declining power. It is initially held constant and it is decreased to zero value. When the source distribution is constant, radial cracks emerge as in the previous example. However, additional circumferential cracks emerge as shown in Figs. 12-16 for decreasing heat source. Such circumferential crack pattern is also observed by Huang et al. (2014) during the power down period. The predicted crack patterns and temperature distributions are shown in Figs. 12-16. As the heat source decreases, the temperature also decrease. It is also worth noting that four dominant radial cracks merge during the cooling down process. 

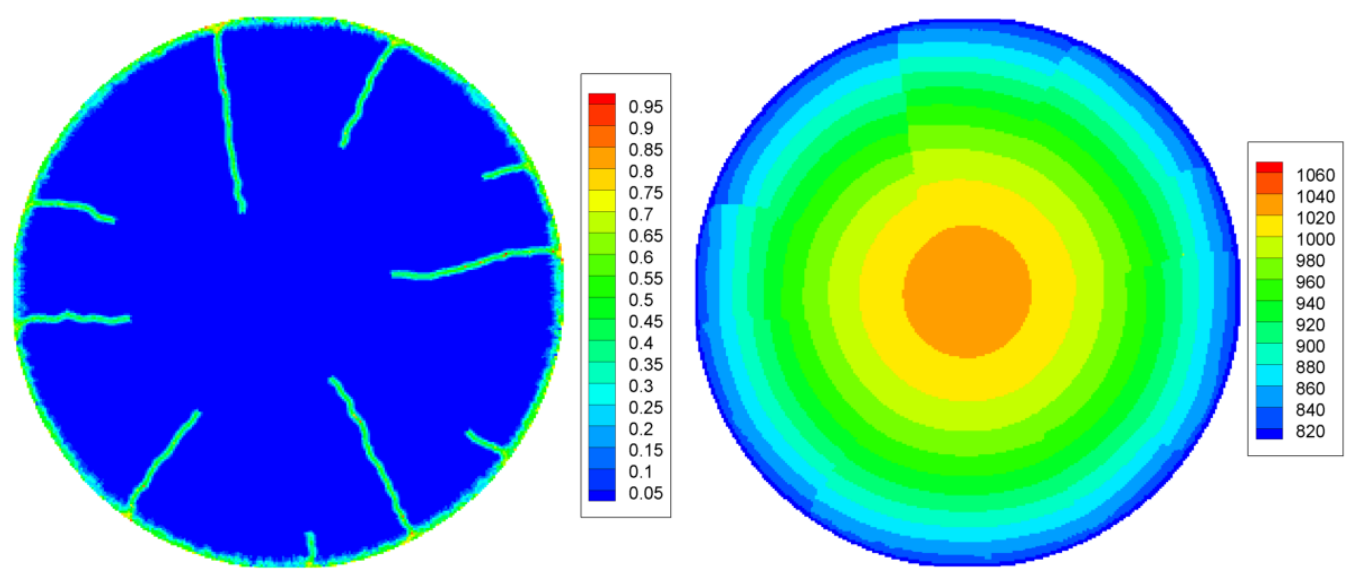

Fig. 12. PD crack initiation and propagation paths, and the corresponding temperature in the fuel pellet at $t=5.4 \mathrm{~s}$
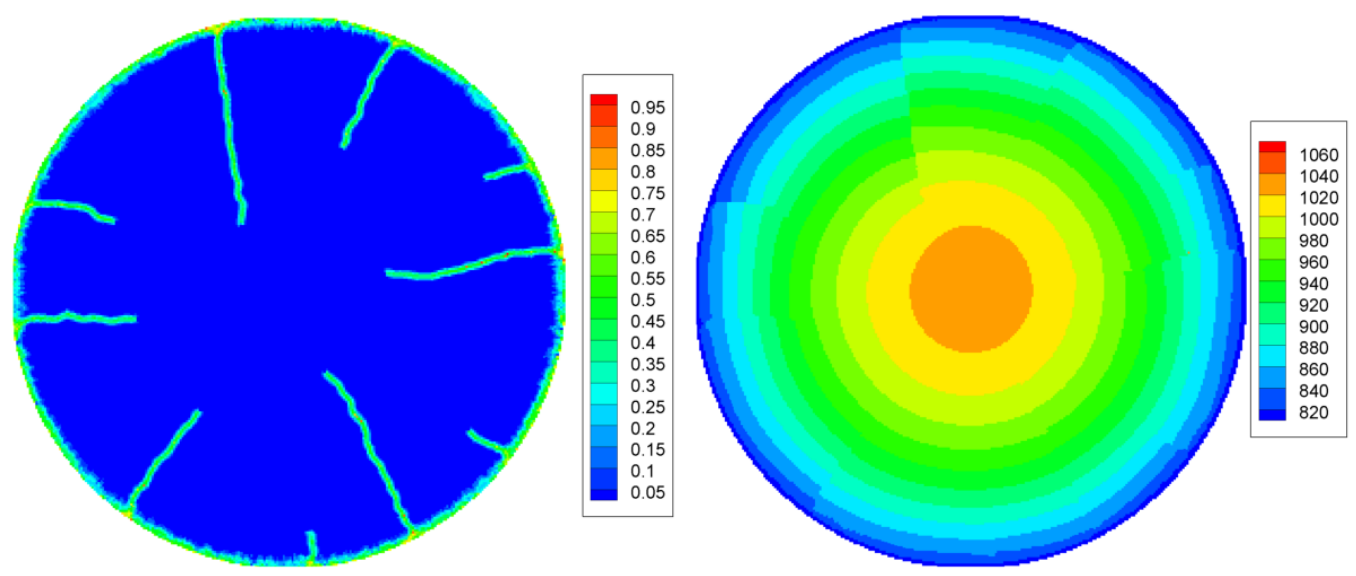

Fig. 13. PD crack initiation and propagation paths, and the corresponding temperature in the fuel pellet at $t=6.3 \mathrm{~s}$ 

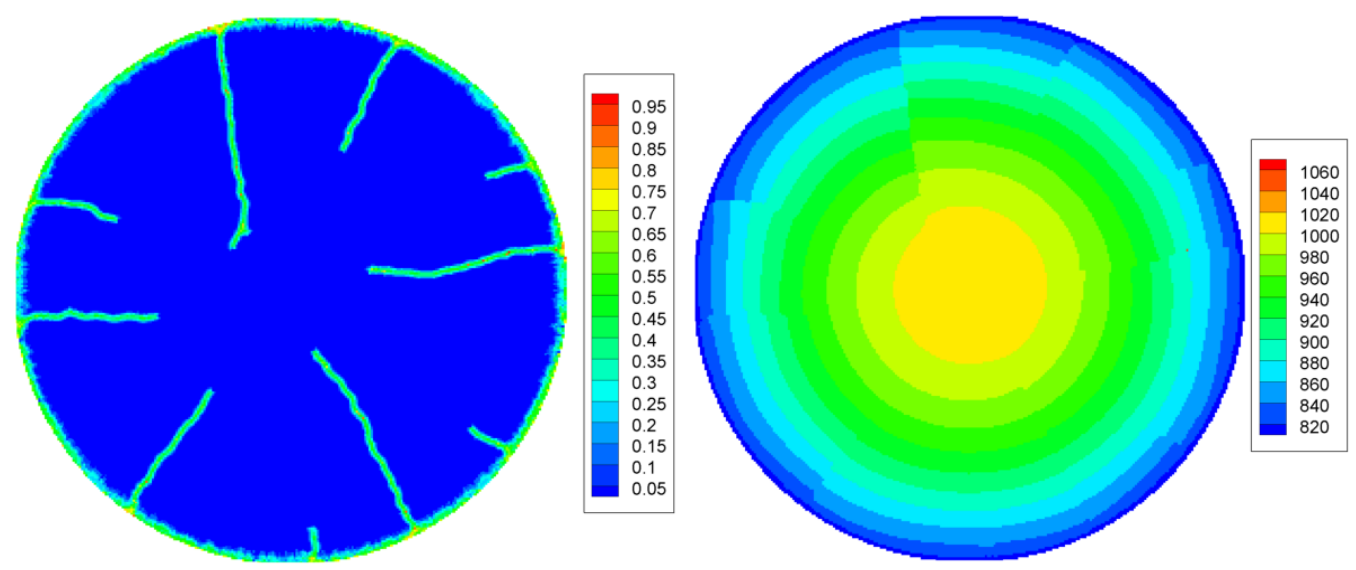

Fig. 14. PD crack initiation and propagation paths, and the corresponding temperature in the fuel pellet at $t=7.2 \mathrm{~s}$
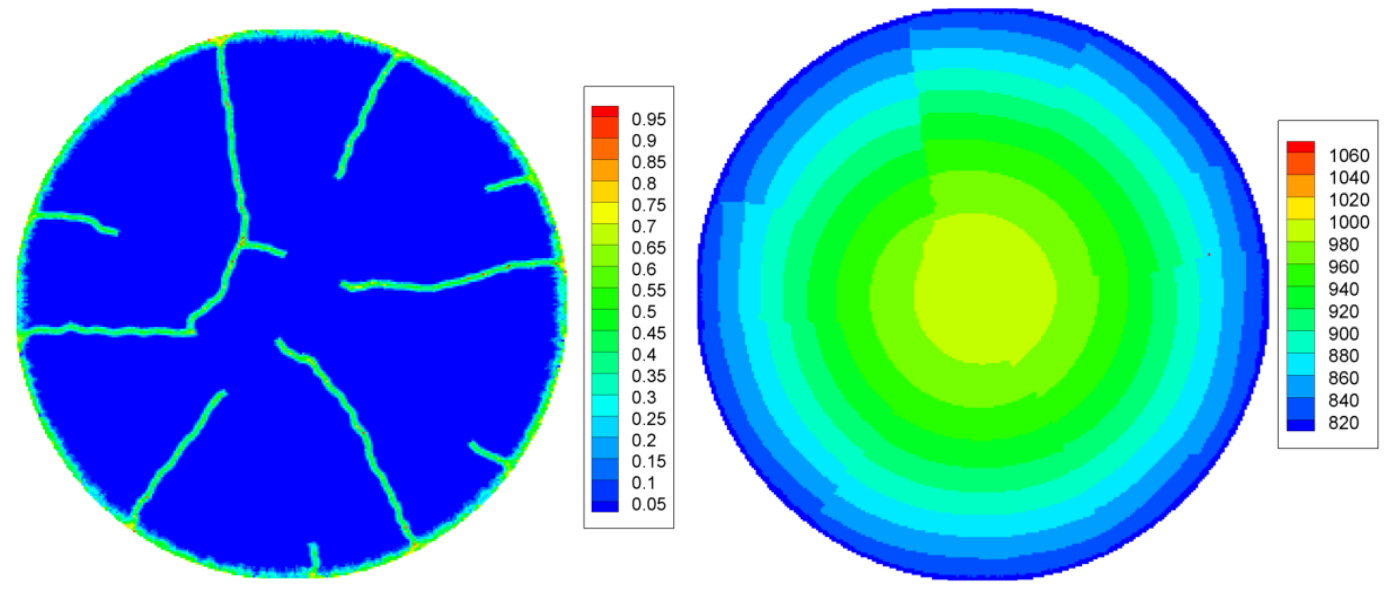

Fig. 15. PD crack initiation and propagation paths, and the corresponding temperature in the fuel pellet at $t=8.1 \mathrm{~s}$ 

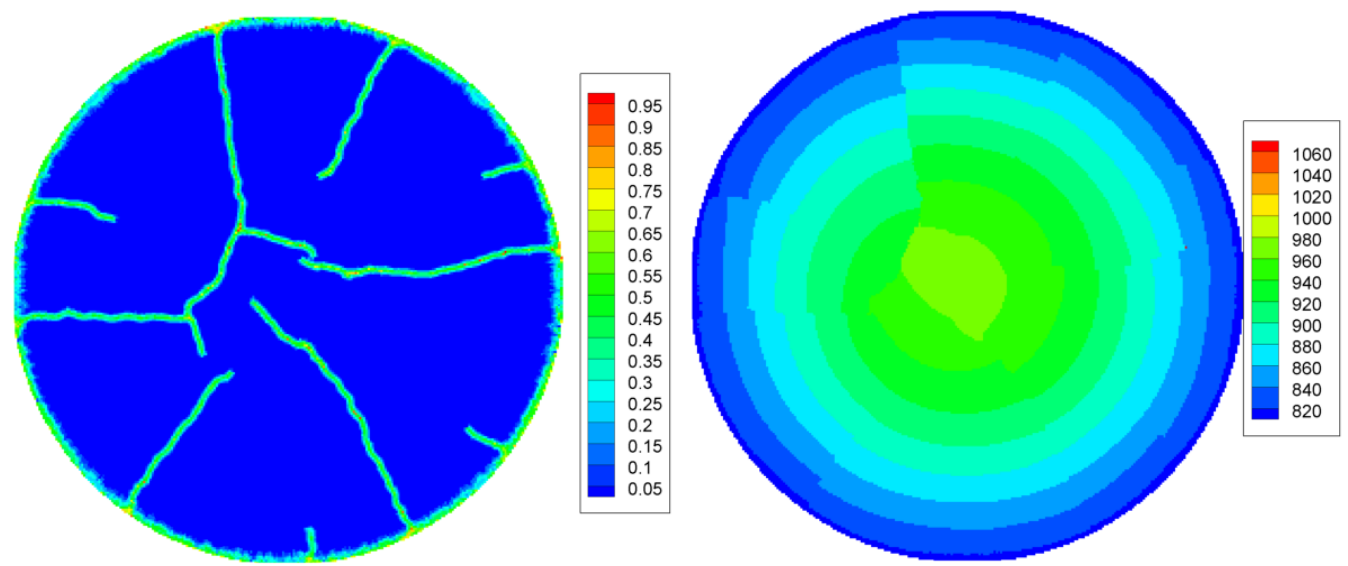

Fig. 16. PD crack initiation and propagation paths, and the corresponding temperature in the fuel pellet at $t=9 \mathrm{~s}$

\subsection{Cracking in a fuel pellet due to varying heat source in the presence of oxygen diffusion} The combined effect of oxygen and temperature diffusion on fuel pellet cracking is shown in Fig. 17. In comparison to the previous problem, it is observed that the crack growth rate is faster due to the increasing temperature caused by the oxygen diffusion. Also, additional small cracks emerge during the initial constant heat source process. Although qualitative, these crack growth patterns are similar to the experimental observations published by Michel et al. (2008) as shown in Fig. 18.

(a)

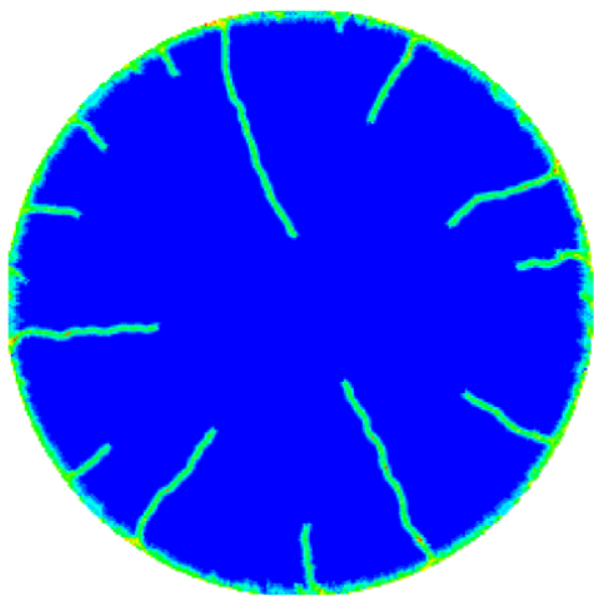

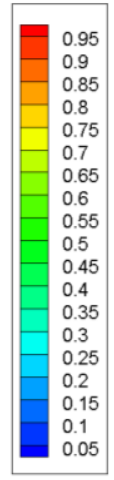

(b)

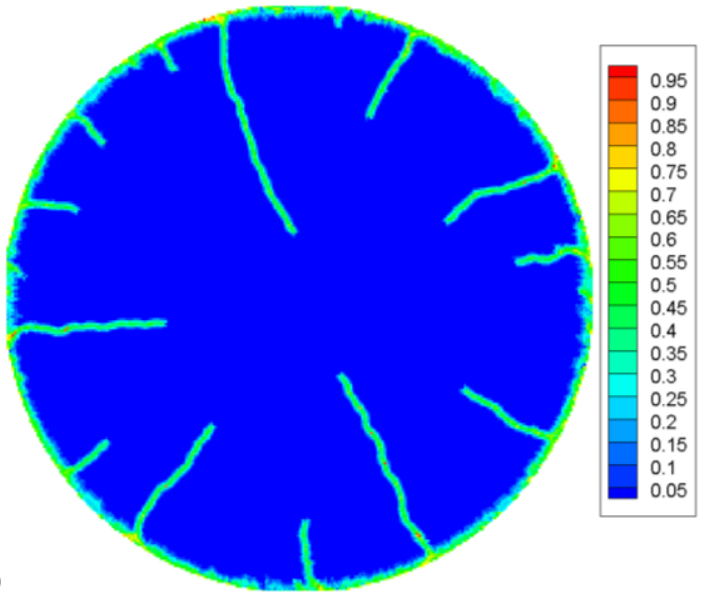


(c)

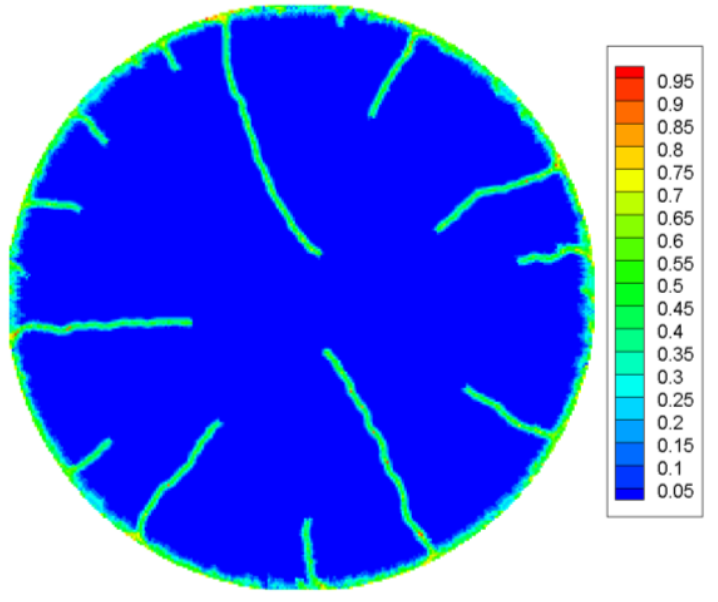

(d)

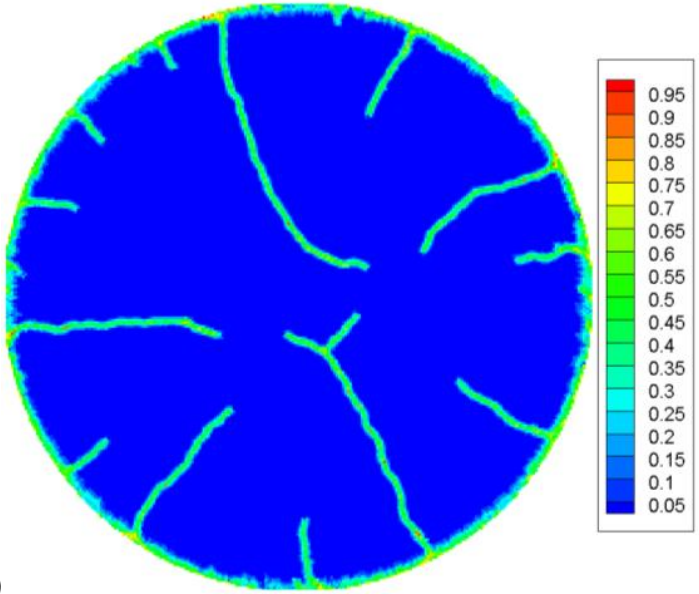

(e)

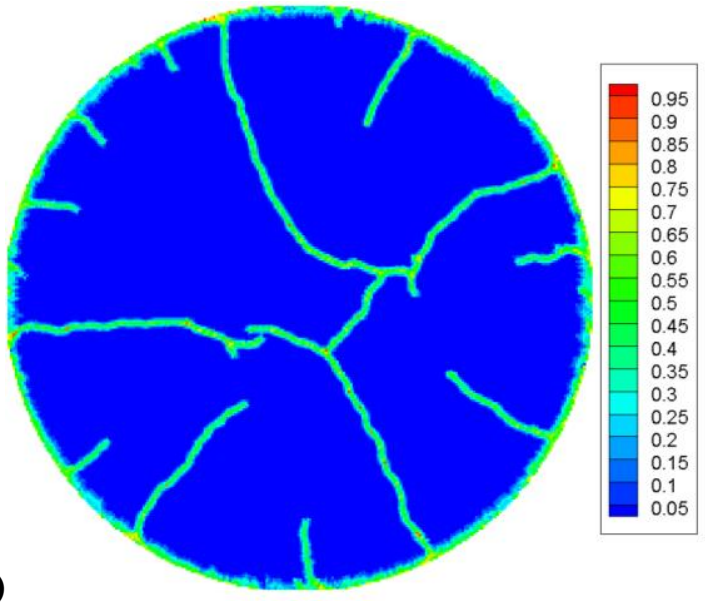

Fig. 17. PD crack initiation and propagation paths in the fuel pellet at a) $t=5.4 \mathrm{~s}$ b) $t=6.3 \mathrm{~s}$ c) $t=7.2 \mathrm{~s}$ d) $t=8.1 \mathrm{~s}$ e) $t=9 \mathrm{~s}$.

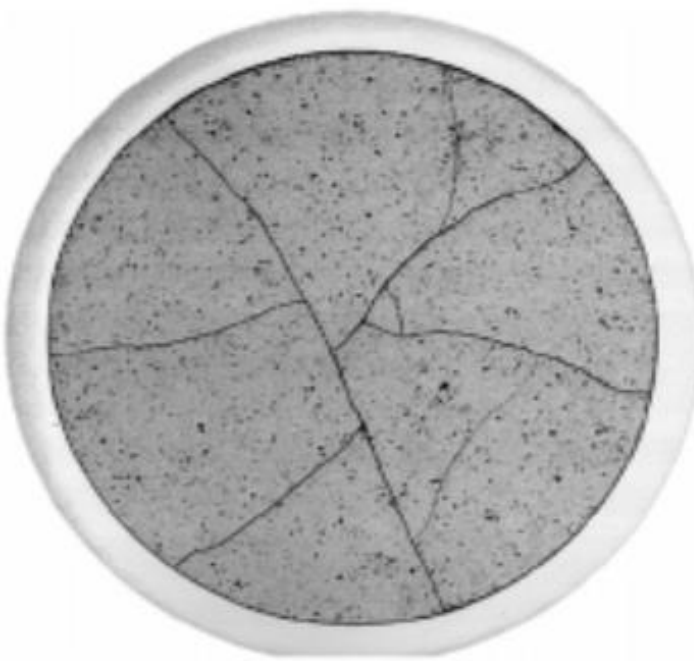

Fig. 18. Experimentally observed fuel pellet cracking by Michel et al. (2008) 


\section{Concluding remarks}

In this study, thermo-mechanical behavior of fuel pellets is investigated by coupling thermal diffusion, oxygen diffusion and the mechanical deformation. It is evident that both thermal diffusion and oxygen diffusion have an effect on the pellet deformation and pellet cracking behavior. The thermal conductivity of the fuel pellet decreases with increasing oxygen concentration. This creates higher temperature profiles at the center. Due to the Soret effect, the increase in temperature gradient also leads to oxygen diffusion towards the center. Higher temperatures at the center creates compressive stress at the center, and tensile stress at the outer part of the pellet. As a result, radial cracks initiate and propagate towards the center. Circumferential cracks are also observed due to power down period. It is also observed that oxygen diffusion causes the pellet temperature to increase, and as a result the crack growth rate becomes faster. The PD model successfully captures the expected cracking behavior. The present PD modeling is also applicable for 3-D analysis to capture the longitudinal cracks in the fuel pellet in addition to the radial and circumferential cracks. The effect of temperature on the critical energy release rate of the material is disregarded. As a future work the interaction between the pellet and the cladding; and the effect of temperature on critical energy release rate can be included.

\section{Appendix}

In classical form, the oxygen flux due to concentration gradient is represented as

$$
\mathbf{J}_{C}=-D \nabla C
$$

As derived by Madenci and Oterkus (2016), the corresponding PD form of the diffusion flux can be represented as

$$
\mathbf{J}_{C}=-\frac{1}{2} \int_{H} f_{D C}\left(C^{\prime}, C, \mathbf{x}^{\prime}, \mathbf{x}, t\right)\left(\mathbf{x}^{\prime}-\mathbf{x}\right) d V_{\mathbf{x}^{\prime}}
$$

with

$$
f_{D C}\left(\Theta^{\prime}, \Theta, \mathbf{x}^{\prime}, \mathbf{x}, t\right)=\kappa_{D C} \frac{C^{\prime}\left(\mathbf{x}^{\prime}, t\right)-C(\mathbf{x}, t)}{\left|\mathbf{x}^{\prime}-\mathbf{x}\right|}
$$

with the parameter $\kappa_{D C}$ which can be expressed as a function of thickness, $h$ and horizon size $\delta$ such as $\kappa_{D C}=\frac{6 D}{\pi h \delta^{3}}$ for $2 \mathrm{D}$ and $\kappa_{D C}=\frac{6 D}{\pi \delta^{4}}$ for $3 \mathrm{D}$.

The PD form of the Fickian flux, $\mathbf{J}_{C}$ representing the flux of oxygen due to concentration gradient can be written as 


$$
\begin{aligned}
& \mathbf{J}_{C}=-\frac{1}{2} \int_{H} \frac{6 D}{\pi h \delta^{3}} \frac{C^{\prime}\left(\mathbf{x}^{\prime}, t\right)-C(\mathbf{x}, t)}{\left|\mathbf{x}^{\prime}-\mathbf{x}\right|}\left(\mathbf{x}^{\prime}-\mathbf{x}\right) d V_{\mathbf{x}^{\prime}} \text { for } 2 \mathrm{D} \\
& \mathbf{J}_{C}=-\frac{1}{2} \int_{H} \frac{6 D}{\pi \delta^{4}} \frac{C^{\prime}\left(\mathbf{x}^{\prime}, t\right)-C(\mathbf{x}, t)}{\left|\mathbf{x}^{\prime}-\mathbf{x}\right|}\left(\mathbf{x}^{\prime}-\mathbf{x}\right) d V_{\mathbf{x}^{\prime}} \text { for } 3 \mathrm{D}
\end{aligned}
$$

By comparing Eqs. (28 1) and (29 2), it is evident the gradient of a scalar can be represented as

$$
\nabla C=\frac{1}{2} \kappa_{J} \int_{H} \frac{C^{\prime}\left(\mathbf{x}^{\prime}, t\right)-C(\mathbf{x}, t)}{\left|\mathbf{x}^{\prime}-\mathbf{x}\right|}\left(\mathbf{x}^{\prime}-\mathbf{x}\right) d V_{\mathbf{x}^{\prime}}
$$

with $\kappa_{J}=\frac{6}{\pi h \delta^{3}}$ for $2 \mathrm{D}$ and $\kappa_{J}=\frac{6}{\pi \delta^{4}}$ for $3 \mathrm{D}$. The components of this gradient can expressed as

$$
\begin{aligned}
& \frac{\partial C}{\partial x}=\frac{1}{2} \kappa_{J} \int_{H}\left(C^{\prime}\left(\mathbf{x}^{\prime}, t\right)-C(\mathbf{x}, t)\right) \frac{\left(x^{\prime}-x\right)}{\left|\mathbf{x}^{\prime}-\mathbf{x}\right|} d V_{\mathbf{x}^{\prime}} \\
& \frac{\partial C}{\partial y}=\frac{1}{2} \kappa_{J} \int_{H} C^{\prime}\left(\mathbf{x}^{\prime}, t\right)-C(\mathbf{x}, t) \frac{\left(y^{\prime}-y\right)}{\left|\mathbf{x}^{\prime}-\mathbf{x}\right|} d V_{\mathbf{x}^{\prime}}
\end{aligned}
$$

The classical form of the oxygen diffusion is of the form

$$
\frac{\partial C}{\partial t}+\nabla \cdot \mathbf{J}=0
$$

or

$$
\frac{\partial C}{\partial t}=-\frac{\partial}{\partial x} J_{x}-\frac{\partial}{\partial y} J_{y}-\frac{\partial}{\partial z} J_{z}
$$

Its PD form can be expressed as

$$
\begin{aligned}
\frac{\partial C}{\partial t}= & \frac{-1}{2} \kappa_{J} \int_{H}\left(\left(J_{x}^{\prime}\left(\mathbf{x}^{\prime}, t\right)-J_{x}(\mathbf{x}, t)\right) \frac{x^{\prime}-x}{\left|\mathbf{x}^{\prime}-\mathbf{x}\right|}\right) d V_{\mathbf{x}^{\prime}} \\
& \frac{-1}{2} \kappa_{J} \int_{H}\left(\left(J_{y}^{\prime}\left(\mathbf{x}^{\prime}, t\right)-J_{y}(\mathbf{x}, t)\right) \frac{y^{\prime}-y}{\left|\mathbf{x}^{\prime}-\mathbf{x}\right|}\right) d V_{\mathbf{x}^{\prime}}
\end{aligned}
$$

and 


$$
\begin{aligned}
\frac{\partial C}{\partial t}= & \frac{-1}{2} \kappa_{J} \int_{H}\left(\left(J_{x}^{\prime}\left(\mathbf{x}^{\prime}, t\right)-J_{x}(\mathbf{x}, t)\right) \frac{x^{\prime}-x}{\left|\mathbf{x}^{\prime}-\mathbf{x}\right|}\right) d V_{\mathbf{x}^{\prime}} \\
& \frac{-1}{2} \kappa_{J} \int_{H}\left(\left(J_{y}^{\prime}\left(\mathbf{x}^{\prime}, t\right)-J_{y}(\mathbf{x}, t)\right) \frac{y^{\prime}-y}{\left|\mathbf{x}^{\prime}-\mathbf{x}\right|}\right) d V_{\mathbf{x}^{\prime}} \quad \text { for 3D } \\
& \frac{-1}{2} \kappa_{J} \int_{H}\left(\left(J_{z}^{\prime}\left(\mathbf{x}^{\prime}, t\right)-J_{z}(\mathbf{x}, t)\right) \frac{z^{\prime}-z}{\left|\mathbf{x}^{\prime}-\mathbf{x}\right|}\right) d V_{\mathbf{x}^{\prime}}
\end{aligned}
$$

\section{References}

Aitken, E. A. (1969). Thermal diffusion in closed oxide fuel systems. Journal of Nuclear Materials, 30, 62-73.

Amaya, M., Kubo, T., and Korei, Y. (1996). Thermal Conductivity Measurements on UO2+ X from 300 to 1,400 K. Journal of Nuclear Science and Technology, 33, 636-640.

Berna, G. A., Beyer, G. A., Davis, K. L. and Lanning, D. D. (1997), FRAPCON-3: A Computer Code for the Calculation of Steady-state, Thermal-Mechanical Behavior of Oxide Fuel Rods for High Burnup, Technical Report NUREG/CR-6534, vol. 2, PNNL-11513.

Brutzel, L.V., Dingreville, R., and Bartel, T. J. (2015) Nuclear fuel deformation phenomena. State-of-the-Art Report on Multi-scale Modelling of Nuclear Fuels, 59-79.

Chernatynskiy, A., El-Azab, A., Tulenko, J. S., and Phillpot, S. R. (2015) Phenomena in thermal transport in fuels. State-of-the-Art Report on Multi-scale Modelling of Nuclear Fuels, 144-173.

Gates, G. A., Cook, P. M. A., De Klerk, P., Morris, P. and Palmer, I. D. (1998). Thermal performance modeling with the ENIGMA code. Proc. of Seminar on Thermal Performance of High Burnup LWR Fuel, France, 301-310.

Gerstle, W., N. Sau, N. and Silling, S. A. (2005) Peridynamic modeling of plain and reinforced concrete structures. SMiRT18: 18th International Conference on Structural Mechanics in Reactor Technology, Beijing, China.

Huang, H., Spencer, B. and Hales, J. (2014). Discrete element method for simulation of early-life thermal fracturing behavior in ceramic nuclear fuel pellets. Nuclear Engineering and Design, 278, 515-528.

Ito, K., Ichikawa, M., Okubo, T. and Iwano, Y. T. (1983). FEMAXI-III, a computer code for fuel rod performance analysis. Nuclear Engineering and Design, 76, 3-11.

Janek, J. and Timm, H. (1998). Thermal diffusion and Soret effect in (U, Me) O $2+\delta$ : the heat of transport of oxygen. Journal of Nuclear Materials, 255, 116-127. 
Kilic, B. and Madenci, E., (2010a), Peridynamic Theory for Thermomechanical Analysis, IEEE Transactions on Advanced Packaging, 33, 97-105.

Kilic, B. and Madenci, E., (2010b), An adaptive dynamic relaxation method for quasi-static simulations using the peridynamic theory, Theor. Appl. Fract. Mech., 53, 194-201.

Kurepin, V. A. (2002). Thermodynamic properties of hyperstoichiometric urania in the UO $2-$ UO 2.25 solid solution range. Journal of NuclearMaterials, 303, 65-72.

Lassmann, K. (1992) TRANSURANUS: a fuel rod analysis code ready for use. Journal of Nuclear Materials, 188, 295-302.

Lucuta, P. G., Matzke, H., and Hastings, I. J. (1996). A pragmatic approach to modelling thermal conductivity of irradiated UO 2 fuel: review and recommendations. Journal of Nuclear Materials, 232, 166-180.

Mella, R. and Wenman, M. R. (2015). Modelling explicit fracture of nuclear fuel pellets using peridynamics. Journal of Nuclear Materials, 467, 58-67.

Michel, B., Sercombe, J., Thouvenin, G., and Chatelet, R. (2008) 3D fuel cracking modelling in pellet cladding mechanical interaction, Eng. Frac. Mech., 75, 3581-3598.

Mihaila, B., Stan, M., Ramirez, J., Zubelewicz, A. and Cristea, P. (2009) Simulations of coupled heat transport, oxygen diffusion, and thermal expansion in UO 2 nuclear fuel elements. Journal of Nuclear Materials, 394, 182-189.

Newman, C., Hansen, G. and Gaston, D. (2009) Three dimensional coupled simulation of thermomechanics, heat, and oxygen diffusion in UO2 nuclear fuel rods. Journal of Nuclear Materials, 392, 6-15.

Madenci, E. and Oterkus, S. (2016), "Peridynamics for Coupled Field Equations," The Handbook of Peridynamics, Edited by F. Bobaru, J.T. Foster, P. Guebelle, S.A. Silling. Taylor \& Francis/CRC Press.

Oterkus S., Madenci E. and Agwai A. (2014) Peridynamic Thermal Diffusion. Journal of Computational Physics, 265, 71-96.

Oterkus, S. and Madenci, E. (2015) Peridynamics for antiplane shear and torsional deformations. Journal of Mechanics of Materials and Structures, 10, 167-193.

Ramirez, J. C., Stan, M. and Cristea, P.,(2006) Simulations of heat and oxygen diffusion in $\mathrm{UO}_{2}$ nuclear fuel rods. Journal of nuclear materials, 359, 174-184.

Rashid, J. Y., Yagnik, S. K. and Montgomery, R. O. (2011) Light water reactor fuel performance modeling and multi-dimensional simulation. JOM, 63, 81-88. 
Sercombe, J., Helfer, T., Federici, E., Leboulch, D., Le Jolu, T., de Ménibus, A. H. and Bernaudat, C. (2016) 2D simulation of hydride blister cracking during a RIA transient with the fuel code ALCYONE. EPJ Nuclear Sciences \& Technologies, 2 (22), 1-9.

Silling, S. A. (2000). Reformulation of elasticity theory for discontinuities and long-range forces. Journal of the Mechanics and Physics of Solids, 48, 175-209.

Silling, S.A., Askari, E., (2005), A meshfree method based on the peridynamic model of solid mechanics. Comput. Struct., 83, 526-1535.

Williamson, R. L. and Knoll, D. A. (2009) Simulating dynamic fracture in oxide fuel pellets using cohesive zone models. Proceedings of SMiRT, 20, 9-14.

Williamson, R. L. (2011). Enhancing the ABAQUS thermomechanics code to simulate multipellet steady and transient LWR fuel rod behavior. Journal of Nuclear Materials, 415, 7483.

Williamson, R. L., J. D. Hales, S. R. Novascone, M. R. Tonks, D. R. Gaston, C. J. Permann, D. Andrs, and R. C. Martineau. (2012) Multidimensional multiphysics simulation of nuclear fuel behavior. Journal of Nuclear Materials, 423, 149-163. 